
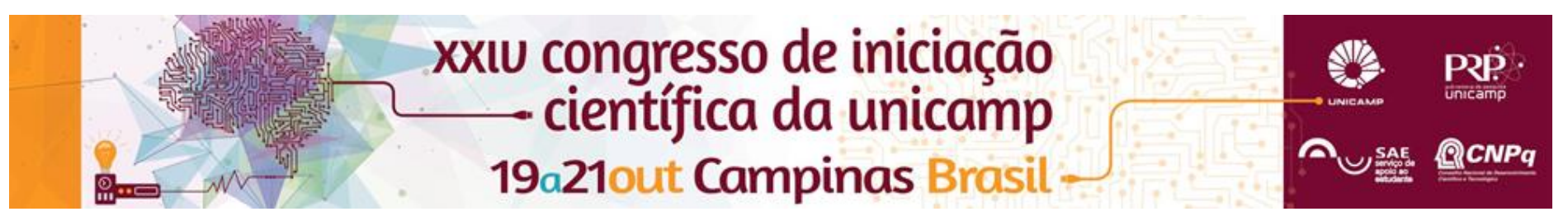

\title{
Projeto de prospecção do potencial de inovação de pesquisa de grupo de pesquisa que pode ser ou não do orientador.
}

\section{Graziele Moreira* (IC), Janaína César (Ger. INOVA), Ana Carolina Gonzaga (Analista INOVA), Livia Aldred (PAEPE INOVA), Raisa R. S. de Gusmão (IC) e Patrícia Franco L. Gestic (Dir. INOVA)}

\section{Resumo}

Este projeto tem como objetivo realizar a prospecção ativa dos grupos de pesquisa da Unicamp, com três frentes de prospecção: i) grupos de pesquisa que possuem convênios P\&D (projetos firmados com empresas) e aprovados na Unicamp através da Câmara para Análise e Aprovação de Convênios e Contratos - CAACC; ii) análise de teses e dissertações que se encontram sob sigilo no Sistema de Bibliotecas da Unicamp - SBU; e iii) docentes de grupos de pesquisa que foram notícia ou teses da Semana do Jornal da Unicamp - JU, porém com ênfase em Eng. Química, Eng. de Alimentos e áreas correlatas. A partir da prospecção, os projetos mapeados são avaliados segundo uma metodologia específica, objetivando identificar e priorizar resultados de pesquisas com maior potencial inovativo (uma solução inventiva para uma demanda tecnológicas existente), sendo que para os resultados com potencial inovativo tem como ação a recomendação para submissão da Comunicação de Invenção $(\mathrm{Cl})$ à Agência de Inovação Inova Unicamp².

\section{Palavras-chave:}

Prospecção, Potencial Inovativo, Inovação Tecnológica.

\section{Introdução}

Este projeto visa a identificação de oportunidades (seja através da proteção da propriedade intelectual - por ex.; patente, programa de computador, material biológico gerada na universidade, seja através da transferência de tecnologia - por ex.; patente e know-how, seja através da criação de uma start-up, etc.) para a Unicamp, pois realiza prospecção ativa junto à comunidade acadêmica da universidade, para detectar e priorizar resultados das pesquisas tecnológicas da Unicamp de maior potencial inovativo (uma solução inventiva para uma demanda tecnológicas existente), sendo que as de maior potencial inovativo são priorizadas sendo recomendada a submissão da Comunicação de Invenção para a Inova Unicamp, Agência de Inovação responsável pela análise de patenteabilidade, definição da estratégia de proteção, bem como busca de um parceiro industrial para transferência de tecnologia.

O principal objetivo desse trabalho é identificar oportunidades de invenções através de mapeamento e identificação de projetos com potencial inovativo e incentivar a proteção da propriedade intelectual gerada na Unicamp.

\section{Resultados e Discussão}

A partir das três frentes de prospecção abordadas no presente projeto, com ênfase em Eng. Química, Eng. de Alimentos e áreas correlatas, foram obtidos os resultados apresentados nas tabelas 1 e 2 .

Tabela 1. Resultados da prospecção* dos grupos de pesquisa da Unicamp separados por área.

\begin{tabular}{|c|c|c|c|}
\hline Áreas & CAACC & $\begin{array}{c}\text { JU - Reporta- } \\
\text { gens }\end{array}$ & $\begin{array}{l}\text { Teses da } \\
\text { Semana }\end{array}$ \\
\hline $\begin{array}{c}\text { Engenharia } \\
\text { Química }\end{array}$ & 1 & - & 4 \\
\hline $\begin{array}{l}\text { Engenharia } \\
\text { de Alimentos }\end{array}$ & 1 & 1 & - \\
\hline Correlatas & 3 & 2 & 10 \\
\hline
\end{tabular}

* Reflete a prospecção apoiada pelo Projeto PIBITI com ênfase em Eng.

Química, Eng. de Alimentos e áreas correlatas.

Tabela 2. Resultados da prospecção* dos grupos de pesquisa da Unicamp separados por frente de prospecção

\begin{tabular}{|c|c|c|c|c|}
\hline Pesquisa & CAACC & JU & SBU \\
\hline $\begin{array}{c}\text { Total avaliado } \\
\text { Pré-selecionadas }\end{array}$ & 584 & 780 & 494 \\
\hline $\begin{array}{c}\text { Declinados na dili- } \\
\text { gência** }\end{array}$ & 5 & 38 & 31 \\
\hline $\begin{array}{c}\text { Não mapeados } \\
\text { Com potencial de }\end{array}$ & 20 & 17 & - \\
\hline $\begin{array}{c}\text { Inovação } \\
\text { Cl recebidas }\end{array}$ & 25 & 20 & 17 \\
\hline
\end{tabular}

* Reflete a prospecção realizada pela equipe de Propriedade Intelectual da Inova Unicamp, incluindo as iniciativas dos Projetos PIBITI 2015/2016, independente da área do conhecimento, no mesmo período de vigência do presente projeto.

${ }^{* *}$ Não atende aos requisitos de patentiabilidade.

***Devido à dificuldade de contato com o docente responsável.

${ }^{* \star *} \mathrm{Cls}$ recebidas anteriormente a prospecção

\section{Conclusão}

Analisando a tabela 2, é possível perceber que todas as frentes de prospecção possuem um grande número de pesquisas, no entanto só uma pequena parcela destas apresenta potencial Inovativo, o que é refletido no baixo número de $\mathrm{Cls}$ recebidas.

\section{Agradecimentos}

Gostaria de agradecer a todos os participantes desse projeto pela colaboração e ao CNPQ.

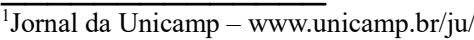
${ }^{2}$ Inova/ Unicamp - http://www.inova.unicamp.br/ 